\title{
Ángel Sanz Briz y Giorgio Perlasca en defensa de los judíos de Hungría ${ }^{1}$.
}

\author{
Ángel Sanz Briz and Giorgio Perlasca in defense of the Jews of Hungary \\ Matilde Morcillo Rosillo \\ Matilde.MRosillo@uclm.es \\ Elena Colitto Castelli \\ Castelli14@gmail.com \\ Universidad de Castilla-La Mancha
}

\section{Resumen}

Este trabajo, que aborda la salvación de los judíos de Budapest ante las persecuciones nazis durante la Segunda Guerra Mundial, tiene por objeto aclarar ciertas partes oscuras sobre los méritos de dos de los protagonistas de tales acciones, en particular de Ángel Sanz Briz y Giorgio Perlasca.

Atención especial require el estudio comparativo de dichos protagonistas por ser el primer trabajo que se ha hecho hasta el presente. Para ello se han utilizado textos, documentales y testimonios inéditos, que han puesto de manifiesto cómo el papel relevante de Perlasca en la defensa de los judíos de Budapest queda reducido en favor de otros diplomáticos.

Palabras clave: Budapest, judíos, Ángel Sanz Briz, Giorgio Perlasca.

\begin{abstract}
This study, which concerns the rescue of the Jews of Budapest from the Nazi persecutions during the Second World War, aims to clarify certain obscure areas about the merits of some of the protagonists of such actions, in particular, Angel Sanz Briz and Giorgio Perlasca.

The comparative study of these protagonists deserves special attention as this is the first essay that has been done so far. That is why texts, documentaries and unpublished testimonies have been used, and they have revealed how the relevant role of Perlasca in the defense of the Jews of Budapest is reduced in favor of the other diplomats.

\footnotetext{
${ }^{1}$ Trabajo presentado el 11 de abril de 2013 en la Universidad LUMSA de Roma en el contexto del seminario Percorsi storici della Shoah. Il buon uso della Memoria. El buen uso de la Memoria es imprescindible para interpretar la Historia en sus diversas facetas y para no ofrecer interpretaciones que fluyan en una sola dirección. . Dicho trabajo fue traducido del italiano al español por Fernando Vara de Rey.
} 
Key words: Budapest, Jews, Angel Sanz Briz, Giorgio Perlasca.

\section{Contexto histórico}

La movilización de los diplomáticos de países neutrales en favor de los judíos perseguidos durante la Segunda Guerra Mundial es mucho más intensa en Hungría, particularmente en Budapest, donde la ocupación nazi es más tardía en comparación con otros estados europeos.

Con el Almirante Miklós Horthy, regente de Hungría, los judíos gozaron de una calma relativa hasta el 19 de marzo de 1944 cuando el ejército alemán ocupó Hungría con el objeto de evitar el abandono temido de los que hasta entonces habían estado con las potencias del Eje. A Adolf Eichmann se le dio la tarea de exterminar la numerosa colonia judía, compuesta de alrededor de 825.000 judíos. En un período de nueve semanas, entre finales de abril y principios de julio de 1944, Eichmann envió a Auschwitz medio millón de judíos húngaros. Las redadas y deportaciones comenzaron en el campo y los que se salvaron huyeron a Budapest para pedir ayuda a los diplomáticos de países neutrales y a la Nunciatura Apostólica, que eran los únicos que podían prestársela. En la capital húngara, después de la primera ola de persecución, sólo quedaron unos 257.000 judíos.

Entre julio y agosto de 1944, Horthy se esforzó por contener las deportaciones, al menos en Budapest, y lo va a conseguir, a pesar de que su gobierno estaba alineado con los alemanes. A decir verdad, influyó mucho una nota de protesta de la Nunciatura Apostólica y los representantes de Suecia, Portugal, Suiza y España.

El 15 de octubre de 1944, el Almirante Horthy, debido a su intento de querer firmar la paz por separado con los Aliados, fue derrocado con el apoyo de Alemania, y subió al poder el líder Ferenc Szálasi del partido pronazi Cruz Flechada. El 19 de octubre Szálasi obligó a los judíos extranjeros a llevar la estrella amarilla y a concentrarse en guetos; además, se comprometió a 'prestar' 50.000 judíos a los alemanes para trabajos forzados (Rother, 2005: 369-370).

\section{La acción del diplomático español Ángel Sanz Briz en defensa de los judíos de Budapest}

Ángel Sanz Briz fue nombrado Secretario de 2a en la Legación de Hungría el 24 de marzo de 1942 y llega a Budapest a tomar posesión el 10 de mayo de 1942 -su primer destino como diplomático había sido El Cairo-. En junio de 1944, Sanz Briz sustituyó a Miguel Ángel de Muguiro que era el Encargado de la Legación de España en la capital húngara desde mayo de 1938 (Lisbona, 2016: 85).

El 21 de agosto de 1944 se reunieron Sanz Briz y los diplomáticos de los países neutrales con el nuncio Rotta para tratar el tema de los judíos. En septiembre, Briz advirtió a España del miedo de la población ante el avance ruso. 
El 19 de octubre, como se sabe, el partido pronazi de la Cruz Flechada dio un golpe de Estado y aprobó las primeras medidas antisemitas. El archivo de la Embajada fue trasladado a Viena, pero quedó totalmente destruido en un bombardeo.

El 24 de octubre, el Ministro de Asuntos Exteriores de España, José Félix de Lequerica, debido a la publicación de dichas medidas antisemitas, a instancia del Congreso Mundial Judío de Washington, dio instrucciones a sus diplomáticos en Budapest de proteger a los judíos españoles que, pese a su origen español, no disponían de dicha nacionalidad, pero que todavía continuaban conservando el idioma español para expresarse. Habida cuenta que los sefardíes en Hungría eran escasos, la protección se extendería también a los judíos húngaros.

Ante la protesta de los países neutrales, Hungría anuló algunas de las medidas enunciadas el 19 de octubre y aceptó, en lo que respecta a España, repatriar a este país a 300 judíos bajo la protección de Sanz Briz. Por cierto, decir que Briz transformó la cifra de 300 judíos en 300 familias para incrementar el número, y luego añadió letras, es decir, 300a, 300b, 300c, etc. para no pasar nunca la cantidad de 300 judíos establecida por el ejecutivo húngaro.

A mediados de noviembre, Szálasi publicó nuevas disposiciones por las que afirmaba que los judíos extranjeros que tuvieran pasaportes de protección de sus naciones podrían salir de Hungría cuando los países neutrales reconocieran al nuevo gobierno húngaro. La fecha de salida sería el 1 de diciembre de 1944 -según Espada (2013: 290), el 13 de noviembre de 1944- hasta entonces tendrían que ir al ghetto. Los judíos, como ocurría a menudo, se convirtieron en una moneda de cambio.

Entre octubre y noviembre de 1944, Sanz Briz, para evitar la deportación de los pocos judíos sefardíes españoles que vivían en Budapest les dio pasaportes españoles regulares, un total de 45. También entregó 235 pasaportes provisionales a otros judíos sefardíes. En realidad, esto era un expediente para proteger un mayor número de personas, porque en algunos pasaportes estaban incluidos los miembros de una familia entera y así aumentaron un total de 322 individuos. Además, les emitió 1898 cartas de protección (Lisbona, 2016: 120). En ellas se decía que el titular de las mismas tenía familiares en España, que pensaban reunirse con ellos y que estaban bajo la protección de la Legación española en Budapest ${ }^{2}$.

Sanz Briz decidió, sin consultar con el gobierno español, alquilar ocho casas para albergar a los judíos que les prestaba protección. El conjunto de 'casas protegidas' por los diversos países neutrales se denomina Ghetto Internacional, gracias al acuerdo que firmaron el gobierno húngaro y las Legaciones de los Estados de Suiza, Suecia, Portugal España y el Vaticano. Por ello, a dicho Ghetto podían ir todos los judíos a los que protegían los paíeses neutrales. En noviembre de 1944, Briz liberó a 30 judíos de las marchas de la muerte, y cuatro días después liberó también a otros 71 judíos (Lisbona, 2026: 85-95).

\footnotetext{
${ }^{2}$ AMAE (Archivo Ministerio Asuntos Exteriores), Renovado, 1716, expediente № 4, Apunte del ministro de Asuntos Exteriores, Madrid, 29 de diciembre de 1944.
} 
En total, Briz protegió a cerca de 2.295 judíos, a los que había que sumar los del salvamento colectivo (Lisbona, 2016: 120). Recordemos que las primeras medidas en favor de los judíos de Hungría no partieron del gobierno español, sino de las comunidades judías de Tánger y Tetuán.

Se sabe que antes de comenzar la Segunda Guerra Mundial, muchos judíos de Hungría salieron del país con destino a dichas ciudades, allí mantenían buenas relaciones con las autoridades españolas en Marruecos; por ello, cuando entraron los alemanes en Budapest en marzo de 1944, las comunidades de Tánger y Tetuán pidieron al gobierno español que les diera visados para que pudieran salir de Hungría a 500 niños y los 70 adultos que les acompañaban con destino a Tánger. Ellos pagarían todos los gastos del viaje, además, no ocasionarían ningún problema porque estaban a punto de salir del país otras 700 personas (Morcillo, 2002: 481). Recordemos que, aunque Muguiro les había concedido el pasaporte español para viajar a Tánger, fue Sanz Briz el encargado de preparar los visados, pero los alemanes se negaron a darles el visado de salida, por lo que fueron recluidos en tres hospicios en Hungría sobreviviendo con ayuda de la Cruz Roja Internacional y de Suecia (Lisbona, 2016).

A finales de 1944, con la ya inevitable derrota de los alemanes y con las comunicaciones interrumpidas, el general Franco podía estar tranquilo que ningún judío de Hungría podría llegar a España, ni siquiera después de la guerra. De hecho, las tarjetas de protección no fueron visados de entrada, los pasaportes provisionales tenían sólo tres meses de validez y los pasaportes españoles regulares eran solo 45, por lo que dado el pequeño número, no constituía un peligro.

El 6 de diciembre de 1944, al tenerse noticias del avance de las tropas rusas hacia Budapest, habida cuenta que España era enemiga del régimen comunista de Rusia, el gobierno español, temiendo por la vida de Sanz Briz, le ordenó que abandonase Hungría -ya había autorizado su marcha el 25 de octubre de 1944- con destino a Suiza. Sanz Briz, antes de partir, puso la Legación bajo la responsabilidad de la Embajada de Suecia (Espada, 2013:125) Sin embargo, la Legación española en la capital húngara continuó trabajando con la responsable de la Cancillería Elisabeth Tourné y su hijo Gastón, con el asesor jurídico, el abogado húngaro Zoltan Farkas, el italiano Giorgio Perlasca del cual hablaremos después- que había obtenido un pasaporte español de Sanz Briz, probablemente, con algunos voluntarios que anteriormente habían pedido protección al diplomático español y que, por razones de seguridad, nunca salieron del edificio (Deaglio, 2012: 61).

Podemos decir que la protección de los judíos llevada a cabo en Hungría por Sanz Briz era beneficiosa para la imagen del ejecutivo español frente a los Aliados, además de ser relativamente fácil. Franco solo tenía que acceder a las recomendaciones de las instituciones hostiles al nazismo y autorizar la entrega de documentos con el sello español, consciente de que Briz había sido capaz de ampliar el número de cartas de protección para los judíos de Hungría.

Por consiguiente, no fue necesario organizar un viaje de repatriación como ocurrió con los judíos de Grecia -o Francia-, donde el Cónsul general de España en Atenas, Sebastián de Romero Radigales, tras numerosas dificultades y poner en riesgo su carrera y hasta su vida, logró repatriar a España a 365 judíos de Salónica (Morcillo, 2008: 24-32; Colitto, 2011: 85-91.). Aunque es cierto que Franco no deseaba la llegada de judíos a España, solo aceptaría la entrada y residencia de los judíos que 
tuvieran una sólida posición económica y que apoyaran el régimen. Le horrorizaba pensar que pudieran entrar grandes masas de judíos y desestabilizar la sociedad española (Morcillo, 2011: 5960). Ahora bien, este temor ya se había dado al proclamarse la Segunda República española en 1931(González, 2004).

\section{El italiano Giorgio Perlasca}

Giorgio Perlasca era el representante de los intereses de Italia en los paises del Este para abastecer de carne al ejército italiano. Perlasca se encontraba pues en Budapest desde octubre de 1942 por razones profesionales cuando Italia, con el nuevo jefe de gobierno nombrado por el rey, Pietro Badoglio, firmó el Armisticio con los Aliados el 8 de septiembre de 1943. Los alemanes, furiosos por esta traición, liberaron a Mussolini, que anteriormente había sido detenido y encarcelado en el mes de julio, y lo pusieron al frente de la República Social Italiana, conocida como República de Salò. Perlasca, que tenía un cargo público tuvo que tomar partido y decidió no adherirse a Salò. Su posición llegó a ser crítica cuando, en marzo de 1944, el ejército alemán ocupó Hungría. Perlasca será internado en un campo junto a algunos diplomáticos y funcionarios italianos. De él escapará con el pretexto de ir a una visita médica durante el golpe de Estado de la Cruz Flechada en octubre de 1944.

Antes de ser internado y después de su fuga, Perlasca buscará protección y exigirá un pasaporte español con nombre falso en la Legación de España como ex combatiente a favor de Franco durante la Guerra Civil para poder salir de Hungría y viajar a España. Las dos primeras veces, con Miguel Ángel Muguiro como Encargado de la Legación de españa en Budapest, el pasaporte le será denegado, porque el Ministerio de Guerra español no encontró nigún documento que probase la participación de Perlasca en la Guerra Civil. La tercera vez, el 13 de octubre de 1944, Ángel Sanz Briz que había sustituido en junio a Muguiro, le concederá el pasaporte, sin ni siquiera consultar al propio Ministerio. Ahora se llamará Jorge, en calidad de empleado de la Legación de España, y lo alojará en los locales de dicha Legación, salvándolo del arresto y de una posible deportación. En realidad, aquellos documentos que probaban que Perlasca había combatido en la Guerra Civil existían, pero no se habían encontrado. Perlasca le corresponderá ayudando en la salvación de los judíos de Budapest, sobre todo los que vivían en las casas protegidas. Trabajó un mes conjuntamente con Sanz Briz y, en particular, con el consejero jurídico de la Legación de España, Zoltan Farkas (Lisbona, 2015: 111-113).

El 6 de diciembre de 1944, con el avance de las tropas soviéticas en Budapest y dado que España no reconocía a la Unión Soviética, con la autorización del gobierno español, Sanz Briz abandonó Budapest y se fue a Suiza (Rother, 2005: 379).

Tras la salida de Sanz Briz, Perlasca, sin conocimiento de las autoridades del Ministerio de Asuntos Exteriores de Madrid, pero sí con la complicidad de Farkas, permaneció en la Legación española para defender a los judíos que estaban bajo la protección de Briz hasta la entrada de los soviéticos 
en Budapest a mediados de enero de 1945, y hacer creer a las autoridades húngaras que España le había nombrado nuevo Cónsul en sustitución de Briz (Espada, 2013: 30 y 286).

Como el mismo Perlasca diría muchos años después, Perlasca se presentó ante el Ministerio de Asuntos Exteriores de Hungría diciendo que él era el nuevo Encargado de la Legación de España, porque Briz había tenido que ir a Suiza por cuestión de trabajo, pero que pronto regresaría con el reconocimiento por parte de España del gobierno de Szálasi. Las autoridades húngaras le entregaron sus credenciales sin más. No olvidemos que Perlasca hablaba un español correcto que había aprendido durante su estancia en España, por lo que pudo engañar más facilmente a las autoridades húngaras.

El gobierno español no estaba al tanto de la existencia de Perlasca ni de su trabajo en favor de los judíos (Avni, 1982: 163-171; Lazo, 1999: 16-28; Harsányi, 1993), pero, gracias a su obra y a que hoy se le llama en Italia 'El impostor', llevó a término la tarea de protección de los judíos que dignamente impulsó Sanz Briz.

\section{Giorgio Perlasca y Ángel Sanz Briz según la reconstrucción del programa televisivo italiano Mixer: 'Omaggio a Giorgio Perlasca' (Homenaje a Giorgio Perlasca).}

Desde hace un tiempo, vienen surgiendo sucesivas polémicas sobre los méritos respectivos de Sanz Briz y Perlasca en Hungría en el salvamento de judíos. Nuestro propósito es aclararlas, al menos en parte, a partir de una serie de textos, documentos, documentales, testimonios inéditos, etc.

Perlasca fue conocido por el público italiano gracias a Mixer, un famoso programa de televisión de Giovanni Minoli. En abril de 1990 Giovanni Minoli, Enrico Deaglio y Gianni Barcelloni promovieron la emisión 'Omaggio a Giorgio Perlasca'. La fama de Perlasca aumentó después en 2002 gracias a la película Perlasca: un eroe italiano ${ }^{3}$. Dicha película se basaba en el programa Mixer y en el libro de Enrico Deaglio 'La banalità del bene'.

Minoli presentaba a Perlasca así:

Giorgio Perlasca no es un hombre cualquiera. Ello está certificado por los reconocimientos que ha recibido por parte de Israel y de Hungría ${ }^{4}$ por haber

\footnotetext{
${ }^{3}$ Perlasca: un eroe italiano, en español: El cónsul Perlasca, de Alberto Negrín, emitida en la RAl en enero de 2002 con ocasión del Día de la Memoria.

${ }^{4}$ El 9 de junio de 1988, el Yad Vashem de Jerusalem reconoció a Giorgio Perlasca como 'Justo entre las Naciones'. Entre 1989 y 1990 se celebran numerosos actos de homenaje a Giorgio Perlasca en Hungría, Israel y Estados Unidos. En abril de 1990 se emitió el homenaje a Giorgio Perlasca para la RAI dentro del programa Mixer. El 6 de diciembre de 1990 se concedió a Giorgio Perlasca la Encomienda de Número de la
} 
improvisado el cargo de Cónsul de España en Budapest en 1944 y por haber -en este desempeño- contribuido de manera determinante a salvar a más de 5.000 familias judías húngaras de la deportación y acaso de la muerte.

Minoli decía que había tenido la oportunidad de reconstruir por entero los pormenores de su vida a partir de una investigación realizada por Enrico Deaglio y Gianni Barcelloni. Deaglio, decía Minoli, exhibía incluso el automóvil que utilizó Perlasca durante 80 días, los 80 días en que ejerció como supuesto Cónsul de España en Budapest ${ }^{5}$.

A la vista de ello, podemos decir que, en realidad, los días que Perlasca actuó en aras de la protección de los judíos fueron algunos menos. Si bien obtuvo su pasaporte español el 13 de octubre de 1944, hasta la partida de Sanz Briz, a principos de diciembre de 1944, se mantuvo a las órdenes del diplomático español. Los días de Perlasca se limitaron por tanto a 39, Lisbona dice 40 días (del 6 de diciembre de 1944 -fecha de la patida de Sanz Briz de Budapest-, al 16 de enero de 1945), día en el que el ejército de la Unión Soviética entró en Budapest ${ }^{6}$, afirma en la transmission.

Los méritos que se atribuyen a Perlasca en relación a la salvación de tantos judíos creemos que no pudieron acaecer en los apenas 40 días. Es cierto que es un período limitado, aunque no es menos cierto que los hechos se sucedían a ritmo vertiginoso, pues la ciudad estaba asediada, se había impuesto el toque de queda, las bombas estallaban y los miembros de la Cruz Flechada que deambulaban por las calles perpetraban a menudo incursiones en las casas protegidas. Ante esta situación, los judíos hacían cola en las embajadas de los países neutrales para pedir una carta de protección, pues apenas podían resistir. Algunos se limitaban a permanecer encerrados en el ghetto o en las casas de protección de los países neutrales (ghetto internacional), u optaban por esconderse.

Hasta la liberación de Budapest por el ejército ruso en enero de 1946, Perlasca pudo cuidar de aquéllos que ya estaban bajo protección de forma heroica, ayudando de manera continuada a los judíos hacinados en las 'casas de protección' españolas e interviniendo enérgicamente en los casos en los que se violaba el principio de extraterritorialidad. No en vano, acostumbraba a desplazarse a la estación de Budapest para con cualquier pretexto rescatar de las SS a aquellos judíos 'protegidos' que fueran arrestados. Sin olvidar que Perlasca probablemente siguió expidiendo cartas de protección fechándolas anterior al 4 de diciembre cuando todavía Briz estaba en Budapest. Ahora bien, hay que tener en cuenta que no se conoce ningún pasaporte ni salvoconducto ni carta de protección con la firma de Perlasca, aunque existen testimonios que recuerdan que cuando se marchó Briz, era Perlasca quien expedía dichas cartas de protección (Lisbona, 2016: 115-122).

Orden de Isabel La Católica, como colaborador de la Embajada de España en Budapest, a propuesta del Director General de África y Medio Oriente del Ministerio de Asuntos Exteriores español, Jorge Dezcallar. El 15 de agosto de 1992 moría Giorgio Perlasca.

${ }^{5}$ Mixer: minutos $1.35 / 4.37$.

${ }^{6}$ http://www.raoulwallenberg.net/es/salvadores/diplomat/perlasca-gran-simulador/ 
Sin embargo, aunque Perlasca expidiera nuevas cartas de protección, la mayor parte de tales documentos, así como el establecimiento de las ocho casas de protección, fueron obra de Ángel Sanz Briz como testimonia el informe que el diplomático español remitió el 14 de diciembre de 1944 al Ministerio de Asuntos Exteriores de España (Rother, 2005:375), y que el propio Sanz Briz recordó a Perlasca en una carta de 4 de diciembre de 1945 en la que le agradecía su actuación en Budapest: "No olvide V. que la decision de meter gente en los locales de la Legación fue de mi propia iniciativa, sin previo permiso de Madrid, y motivada por el terror que entonces reinaba en la capital húngara" (Espada, 2013: 294).

Como ya se ha dicho antes, al inicio del programa Mixer se afirmaba que 'Perlasca había contribuido a la salvación de más de 5.000 familias judías', de manera que pareciera que todo el mérito le correspondió a él exclusivamente al emitir más de 5.000 documentos y fundar ocho casas de protección ${ }^{7}$. Sin embargo, pensamos que resulta más que improbable que la acción salvadora se hubiera llevado a cabo únicamente por mérito suyo. Esta opinión es también compartida por Espada (2013). Lisbona (2016: 115-122), por su parte, señala que el número de personas salvadas por Perlasca es dificil de cuantificar, pues no existen datos seguros, aunque de forma general se dice que fueron cerca de 5.200 personas. Ahora bien, las únicas cifras que se pueden comprobar con datos reales son las Listas de Sanz Briz incluidas en el informe que, como se sabe, Briz envió a Madrid el 14 de diciembre de 1944 desde Berna y que, como ya se ha comentado anteriormente, fueron 45 pasaportes ordinaries, 235 pasaportes provisionales y 1898 cartas de protección. En total, 2295.

Sin embargo, en el caso de Ángel Sanz Briz muchos historiadores coinciden en atribuirle el salvamento de cerca de 4.500 personas. Se trata de una cifra muy alta, si bien, aquí hay que incluir las dos operaciones de salvación colectiva. En consecuencia, Sanz Briz habría salvado más de 4.500 judíos entre julio y diciembre de 1944, además de otra acción en favor de 1.200 personas (Morcillo, 2013). A la vista de ello nos pregutamos: ¿es verosímil que Pelasca salvara 5.000 personas en apenas 40 días? Las cifras no encajan, salvo que, como señala Lisbona (2016: 122), a los 4500 protegidos por España y que fue obra, sin ninguna duda, llevada a cabo por Briz, se podrían añadir otras 500 personas que, a pesar de su dificil control e identificación, muy probablemente fueron protegidas por Perlasca durante los 40 días que estuvo como Cónsul, sumando así los 5000 judíos de los que se habla, y que también podría haber alquilado otras cuatro casas más de protección.

Volvemos al documental para constrastar, a juicio de los autores de dicho documental, quién fue Giorgio Perlasca, cómo conoció a Ángel Sanz Briz, cómo discurrió su relación con el diplomático español y, sobre todo, por qué Briz dejó Budapest.

Deaglio sostiene que una vez que Perlasca obtuvo la ciudadanía española propuso a Sanz Briz permanecer en la sede de la Legación a fin de prestar ayuda a los judíos refugiados. Lo cierto es que Perlasca no sabía dónde ir. Así que Sanz Briz lo acogió y lo protegió de los alemanes que le reclamaban. Pero atención -prosigue Minoli- porque es en este punto donde se produce el primero

\footnotetext{
${ }^{7}$ Mixer: minutos $24.20 / 25.54$.
} 
de los muchos giros inesperados que se suceden en estos acontecimientos: "el Cónsul español huye, abandona Budapest y se refugia en Suiza. Perlasca permanece solo, como único responsable de la Legación en una ciudad asediada",

Se concluye, por tanto, en Mixer que Sanz Briz huyó y se refugió en Suiza, una tesis que se reafirma en la ficción: 'Perlasca: un eroe italiano', y que pone de manifiesto el desacuerdo de los descendientes de Sanz Briz quienes aducen que no se trató de una huida sino que el diplomático fue destinado a Berna en aras de su propia seguridad. Así lo afirma Deaglio: "tiene que salir en secreto porque su gobierno no ha reconocido al gobierno húngaro de la Cruz Flechada" (Deaglio, 2012: 67). Esta interpretación de la partida de Sanz Briz se cita en muchos sitios y artículos y es refutada por numerosos historiadores, entre los que cabe destacar a Rother, Espada, etc. (Rother, 2005; Espada, 2013).

En 2011 se estrenaron el largometraje español El Ángel de Budapest y el documental del mismo nombre dedicado a Ángel Sanz Briz. Los breves espacios que tratan sobre la figura de Perlasca lo recrean como un personaje muy positivo. En ambas producciones se afirma que Perlasca contribuyó a terminar la misión iniciada por Sanz Briz, y se subraya que uno y otro han sido reconocidos como 'Justos entre las Naciones' por el Yad Vashem de Jerusalem. Puede decirse, pues, que desde España se percibe el logro de ambos de manera más equilibrada que desde Italia.

Es interesante también poner de manifiesto el testimonio de la poetisa judía Eva Lang quien, junto con su familia, fue favorecida por la Legación de España en Budapest con las cartas de protección colectiva 200 y 201 otorgadas por Sanz Briz. Eva y sus parientes fueron, sin embargo, apresados por soldados húngaros que se negaron a reconocer los efectos de las cartas de protección de un país neutral y les condujeron a un campo de concentración próximo a Budapest el 13 de noviembre de 1944. Afortunadamente, Sanz Briz se enteró de lo ocurrido y envió a un representante con el objetivo de liberar a toda la familia Lang y tramitar su alojamiento en una casa bajo bandera Española (Deaglio, 2012: 29-32).

Cuando Eva Lang fue entrevistada en el programa Mixer relató que en la casa de protección dependiente de la Embajada de España en la que permaneció refugiada junto a otros 650 judíos y niylas -milicia húngara de ideología filonazi- trataron de atacar el edificio en tres ocasiones y fue Perlasca quien consiguió impedirlo.

Sin embargo, en su testimonio, Eva omite el hecho de que su hospedaje en la casa de protección se debió a la acción de Sanz Briz y, aunque cita a otros diplomáticos de países neutrales a los que agradece cuánto hicieron en favor de los judíos, en ningún momento nombra a Sanz-Briz ${ }^{9}$. Parece como si tal omisión sirviera para exaltar el papel de Perlasca. No obstante, Eva Lang fue de nuevo

\footnotetext{
${ }^{8}$ Mixer: minutos 7.32 / 8.57.

${ }^{9}$ Mixer: minutos 21.50 / 22.559-
} 
entrevistada en 2008 en el documental de producción Española, 'El Angel de Budapest', y en esa ocasión manifiestó que nunca habría podido olvidar lo mucho que Sanz Briz hizo en favor de ella y de su familia (Sella, 2011).

A la vista de ello, cabe incluso pensar que Eva hubiera sido salvada por el esfuerzo de ambos, Sanz Briz y Perlasca, en dos avatares diversos: primero, en el campo de internamiento y segundo, en la casa de protección española. Ello corroboraría la tesis de que Perlasca ayudó a aquéllos que ya estaban bajo la protección de Sanz Briz (Rother, 2005: 379).

Los dos protagonistas desempeñarían, entonces, papeles complementarios en el empeño de salvación de los judíos de Budapest, si bien fue Sanz Briz quien realizó un papel preponderante a la hora de expedir la mayor parte de las cartas de protección y de organizar, a imagen de otros diplomáticos de países neutrales, las casas de protección. Fue también Sanz Briz quien ingenió la fórmula de multiplicar los documentos de manera que aparentemente se respetaba el número oficial de 300 y, una vez que terminó su mandato, Perlasca completó valientemente su obra. También resulta relevante, a fin de disipar algunas zonas oscuras, reiterar que Sanz Briz acogió a un Perlasca perseguido por los alemanes y le otorgó un pasaporte español, un techo y una responsabilidad, y que Sanz Briz no huyó sino que su propio gobierno decidió destinarle a Berna por los motivos ya expuestos. Uno y otro recibirían el honorable título de 'Justos entre las Naciones' por parte de Yad Vashem de Jerusalem, Sanz Briz en 1966 -oficialmente en 1989- ${ }^{10}$ y Perlasca en 1988.

\section{Giorgio Perlasca y Raoul Wallenberg según la reconstrucción de Mixer}

Volvemos de nuevo a Mixer, habida cuenta que Giorgio Perlasca esgrime su propia versión de los hechos que impidieron la criminal destrucción de los dos ghettos de Budapest y de los judíos hacinados allí.

Sostiene Minoli: "Perlasca realizó su obra maestra. Dado que tenía conocimiento del terrible plan relativo a los ghettos de Budapest promovió una reunión con el Ministro del Interior húngaro con el propósito de abortarlo".

En palabras de Giorgio Perlasca:

... Así, visité al Ministro Vajna quien me dejó clara su intención de ejecutar semejante plan. Yo quedé atónito. En el último momento se me ocurrió someterle a una especie de chantaje...

\footnotetext{
${ }^{10}$ Sanz Briz recibió el título de 'Justo entre las Naciones' por el Yad Vashem de Jerusalem el 8 de octubre en 1966, pero el gobierno franquista impidió que se diera a conocer públicamente, porque España no mantenía relaciones diplomáticas con Israel en aquel momento, por lo que hubo que esperar a 1989 para que Briz fuera nombrado a título póstumo oficialmente 'Justo entre las Naciones' por el Yad Vashem de Jerusalem.
} 
Al final, Vajna cedió, pude convencerlo dijo Perlasca ${ }^{11}$.

Aquellos que creían que este plan de los nazis había existido realmente (historiadores y testimonios de la época), se inclinaban a pensar que aquello no fue llevado a cabo gracias al diplomático sueco Raoul Wallenberg, quien salvó con sus cartas de protección a varios miles de personas ${ }^{12}$.

Ciertamente, Wallenberg contaba con un amplio poder de intervención y de negociación muy sólido y profesaba un notable respeto a Perlasca. Wallenberg fue designado con la misión de salvar a los judíos por parte del War Refugee Board y de la Inteligencia estadounidense con la cobertura diplomática de un respetable país neutral como era Suecia. A estos efectos llegó a Budapest en julio de 1944, en tanto que Perlasca emprendió su labor de cooperación con Sanz Briz hacia finales de octubre. Parece, por tanto, altamente improbable que, si existía un plan de destrucción de los ghettos y sus habitantes, el mérito de haberlo frustrado se pudiera atribuir a Perlasca. Tampoco es plausible deducir que el Ministro del Interior húngaro tuviera el poder de detener tan siniestro proyecto. Es probable que el único individuo que hubiera podido detener semejante masacre fuera el General August Schmidthuber, comandante de las tropas alemanas desplazadas a Hungría. Y diversos testimonios dicen que Wallenberg había encontrado un intermediario para hablar con el general (Bierman, 1996).

El 17 de enero de 1945 Wallenberg fue convocado en el cuartel general soviético de Debrecen, al este de Budapest. En todo caso, partió en su coche en compañía de su conductor y con escolta soviética. Raoul Wallenberg no fue visto nunca más, y su desaparición planea aún hoy como un misterio. Muy probablemente fue arrestado por los soviéticos y asesinado en el transcurso de los años en algún presidio de Moscú. En consecuencia, jamás se pudo conocer su valioso testimonio acerca del episodio relativo a los ghettos de Budapest.

Perlasca sentía admiración por Wallenberg y no le agradaban los diplomáticos de Carrera (Deaglio, 2016: 66) así que tal vez se identificó más con él que con Sanz Briz, hasta el punto de atribuirse a sí mismo el resultado de un delicado trámite que solo Wallenberg podía llevar a término según lo razonado anteriormente.

\section{Conclusiones}

\footnotetext{
${ }^{11}$ Mixer: minutos 27.35/31.50.

12 Sobre la acción de Raoul Wallenberg, puede verse: Grundber S. http://www.raoulwallenberg.net/es/ [Consultada el 12/7/2017].
}

Larsson http://www.raoulwallenberg.net/es/wallenberg-44/biografia-raoul-wallenberg/ [Consultada el 215-2019] Véase el testimonio de Miriam Herzog, http://www.yadvashem.org/ [Consultada el 8-8-2016]. 
Hemos abierto un breve paréntesis sobre el tema de Perlasca y Wallenberg para subrayar que Perlasca en sus relatos parece haber tenido una tendencia a amplificar su papel, si no a atribuirse empresas no realizadas por él o no sucedidas.

Del estudio realizado se deduce que Sanz Briz y Wallenberg fueron indiscutibles protagonistas de la salvación de los judíos de Hungría. Resulta difícil pensar que Perlasca fuera el héroe solitario capaz de salvar a un elevado número de personas en apenas 40 días y de impedir la masacre en los ghettos de Budapest. Y, por otro lado, la única persona que podría haber aclarado, y posiblemente reducido el papel de Perlasca, en todo el asunto fue el abogado húngaro Zoltan Farkas, asesor legal de la legación española que, como se ha dicho, había continuado con Perlasca la tarea de proteger a los judíos de Budapest. Habiendo trabajado desde el principio en la operación de rescate y siendo un hablante nativo de húngaro, sin duda ha desempeñado un papel fundamental en todo el asunto. El pobre Farkas murió; se cree que ocurrió un accidente durante su huida de la legación española cuando los soviéticos entraron en Budapest (Espada, 2013: 207). Así que ni siquiera él podía decir nada de lo que había pasado después de la partida de Sanz Briz. Espada, aunque reconoce, al final de su libro, a Perlasca como un héroe, tiene unas palabras muy duras hacia él: "Hay un delicado flanco moral en sus exageraciones y en sus imposturas verdaderas! Hay que ser preciso con los muertos" (Espada, 2013: 215).

Sanz Briz fue, en definitiva, quien concedió cartas de protección a casi 5.000 judíos y quien los alojó en las 'casas de protección' librándoles de la deportación.

Wallenberg, dada su particular condición, mantuvo la interlocución con los altos mandos alemanes que, al cabo, tenían el poder de decisión sobre la 'solución final', y disponía de recursos en absoluto comparables a los de Perlasca que le llevaron a una negociación compleja que pudo decidir el destino de los ghettos de Budapest.

Perlasca fue un hombre audaz y dotado de un fuerte sentido práctico que le condujo a proseguir la labor de salvación emprendida por Ángel Sanz Briz. Todo ello es un enorme mérito que no se ha de olvidar, pero que debe ser valorado en su justo término. En cualquier caso, los tres personajes salvaron a miles de judíos húngaros del Holocausto y, en reconocimiento a su labor, los tres fueron nombrados 'Justos entre las Naciones' por el Vad Yashem de Jerusalem.

\section{BIBLIOGRAFÍA}

Anger, P. (1981), Junto a Raoul Wallenberg en Budapest: memorias de los años de guerra en Hungría. Nueva York.

Avni, H. (1982), España, Franco y los judíos, Madrid: Altalema.

Bierman, J. (1996), Justo Gentil: La historia de Raoul Wallenberg, el héroe desaparecido del Holocausto, Reino Unido: Penguin Books. 
Carcedo, D. (2000) “Ángel Sanz Briz. Un español ante el drama judío”, Historia y Vida, n 321, Madrid: 36-45.

Carcedo, D. (2005), Un español frente al Holocausto, Barcelona: Temas de Hoy.

Colitto, E. (2011a), "Memoria familiare e Memoria collettiva nella testimonianza di Elena Colitto" (nipote di de Romero), en Memoria familiare e Memoria collettiva. In difesa degli ebrei di Grecia durante la Shoah. Roma: Università Lumsa e Associazione Tincani: 85-91.

Colitto, E. (2011b), "Tre testimonianze in favore di Sebastian de Romero", Memoria familiare e Memoria collettiva. In difesa degli ebrei di Grecia durante la Shoah, Roma: Università Lumsa e Associazione Tincani: 93-100.

Deaglio, E. (2012), La banalità del bene, Milán: Feltrinelli, (primera edición, 1991).

Eiroa, M. (2001), Las relaciones de Franco con Europa Centro-Oriental (19391955). Ariel: Barcelona.

Espada, A. (2013), En nombre de Franco. Los héroes de la Embajada de España en el Budapest nazi. Barcelona: Espasa.

Franchi, C. (2014), Giorgio Perlasca e Raoul Wallenberg. Ricordando. Aracne: Ariccia, 2014.

González, I. (2004), Los judíos y la Segunda República, 1931-1939, Madrid: Alianza.

Grundber, S., Las circunstancias que rodean la desaparición de Raoul Wallenberg en Budapest, http://www.raoulwallenberg.net/es/. [Consultada el 20/8/2017].

Hallenstein, D., Zavattiero, C. (2010), Giorgio Perlasca: un italiano scomodo: vita e aventura di un fascista che da solo salvò migliaia di ebrei. Chiarelettere.

Harsanyi, I. (1993), “Actividades de la Diplomacia española en defensa de los judíos de Budapest”, Cuadernos del Holocausto, 2

http://www.academia.edu/1690201/_El_hispanismo_en_la_Europa_centro-oriental_[Consultada el 17/6/2017].

Harsanyi, I. (1993), "Lista de los judíos protegidos por la Legación española en tiempos de la persecución", 3: 46-53.

Indelicato, A. (2002), "Perchè fu ignorato Giorgio Perlasca, 'l'impostore' che salvò gli ebrei: una lettera inedita e accorata all'ambasciatore Paolo Vita-Finzi”, Nuova Storia Contemporanea, $\mathrm{n}^{\circ}$ 6, Florencia: 125-132.

Jansen, M. (2008), “Giorgio Perlasca, 'Giusto tra le nazioni' e 'eroe italiano'. Memoria collettiva e memoria privata: il ricordo della Shoah come politica sociale”, en Stefania Lucamante, Monica 
Jansen, Raniero Speelman. Silvia Gaiga. Italianistica Ultraiectina 3. Igitur, Utrecht Publishing \& Archiving Services: Utrecht, 2008.

Larsson, J., Biografía Raoul Wallenberg's, http://www.raoulwallenberg.net/es. [Consultada el $10 / 7 / 2017]$.

Lazo, A. y otros (1999), "España hizo muy poco por los judíos en la Segunda Guerra Mundial”, La Aventura de la Historia, 5 :16-28.

Levine, P. (2010), Raoul Wallenberg in Budapest: Myth, History and Holocaust, London: Vallentine Mitchell.

Lisbona, J.A. (2015), Más allá del deber. La respuesta humanitaria del Servicio Exterior frente al Holocuasto, Madrid: Ministerio de Asuntos Exteriores y de Cooperación.

Lugaresi, G. (2004), Perlasca. Il silenzio del giusto. Mostra antologica su Giorgio Perlasca. Ascoli Pic, eno: Servigliano.

Márai, Sándor, Memoir of Hungary 1944-1948. Corvina: Budapest, 1991

Marquina, A. - Ospina, G.I. (1987), España y los judios, siglo XX. La acción exterior, Madrid: Espasa Calpe.

Marquina, A. (2000), “La España de Franco y los judíos”. En Uriel Macías Kapón, Yolanda Moreno Koch y Ricardo Izquierdo Benito (coords.), Los judíos en la España contemporánea: historia y visiones, 1898-1998. Cuenca: Universidad de Castilla-La Mancha: 191-200.

Martin de Pozuelo, E. (2012), El franquismo, cómplice del Holocausto, Barcelona: La Vanguardia.

Martín, J. (2016), El ángel de Budapest: la lista de Sanz Briz. El Oscar Schindler Español. Barcelona: Ediciones B.

Morcillo, M. (2002), “Las Relaciones entre el Régimen franquista y Hungría durante la Segunda Guerra Mundial. Petición de entrada de judíos procedentes de Hungría en el Protectorado Español en Marruecos", Anales de Historia Moderna y Contemporánea", 18, Murcia: Departamento de Historia Moderna y Contemporánea de la Universidad de Murcia: 481.

Morcillo, M. (2008a), S. R. Radigales y los sefardíes de Grecia, 1943-1946, Madrid: Casa Sefarad, Instituto Cervantes de Atenas, Universidad de Castilla-La Mancha.

Morcillo, M. (2008b), "La comunidad sefardita de Salónica. Cuestión del reconocimiento de la nacionalidad española: desde la Primera a la Segunda Guerra Mundial”, Sefárdica, Buenos Aires: Centro de Investigación y Difusión de Cultura Sefardí: 46-58.

Morcillo, M. (2011), "L’opera del Console Sebastián de Romero Radigales per il salvatagio degli ebrei di Grecia”, Memoria familiare e Memoria collettiva. In difesa degli ebrei di Grecia durante la Shoah, Roma: Università Lumsa e Associazione Tincani: 43-63. 
Negrin, A, (dir.) (2002), Perlasca: un eroe italiano, Italia: RAI.

Ojeda M. (2011), Una introducción al antisemitismo y la Shoah en Hungría (1867-1945). Saarbrücken: Editorial académica española:

Oliveros, L. (dir.) (2011), El Ángel de Budapest, Madrid: Filteam, Boomerang TV, RTVE.

Paldiel, M. (2007), Diplomat Heroes of the Holocaust. Jersey City: KTAV.

Payne, G. (2008), Franco y Hitler. España, Alemania, La Segunda Guerra Mundial y el Holocausto. Madrid: La Esfera de los Libros.

Perlasca, G. (1997), L’Impostore. La memorie dello Schindler italiano. Bolonia: Il Mulino.

Rother, B. (2005), Franco y el Holocausto, traducción de Leticia Artiles Gracia, Madrid: Marcial Pons.

Sella, J. (dir.) (2011), Documental, El Ángel de Budapest, España: TVE.

Suárez, E. (2007), Corresponsal en Budapest, Madrid: Fundación Mapfre.

Zerbini, S. (2006), "Ducumentazione spagnole su Giorgo Perlasca e la sua opera umanitaria in favore degli ebrei ungheresi”, Spagna Contemporanea, $\mathrm{n}^{\circ}$ 30: 171-195.

Wallenberg, R. (1995), Letters and dispatches, 1924-1944, Filadelfia: Arcade Publishing. 